\title{
Application of Big Data Analysis on Higher Education Based on the Regional Economy
}

\author{
Zhangrui \\ Jilin Business and Technology College, Changchun, China \\ asmwh2015@163.com
}

Keywords: Regional Economy, Highly Skilled Personnel, Personnel Training.

\begin{abstract}
From the macroscopic background of Chinese economic development view, the key of the economic boom and the great rejuvenation is talented people. At present, our country is in the way of speed up the economic development and the upgrading of the industrial structure. In this paper, technology as the example, elaborated hour to undertake the regional economic environment of higher occupation education construction, in particular to deep the reform of talents training pattern. The professional construction needs corresponding strategic support, including the sound of the long-term stability of school-enterprise coalition cooperation mechanism, improve the professional quality of teaching evaluation system of supervision, comprehensive social service ability and the ability of radiation. We need to pay special attention to the cooperation of school and enterprise in the mechanism, the talent training mode of work-study combination construction, make the school relies on an enterprise and form real occupation education mode.
\end{abstract}

\section{Introduction}

Regional economic means certain socio-economic conditions, according to the geographical nature, intrinsically linked economic development of the flow of goods, ethnic and cultural traditions, and economic and social development needs of the Commonwealth in the form of a certain area. The regional economy unlike administrative divisions strictly, which are in all economic regions within the regional economy. There is no affiliation between the upper and lower administrative organization, together with each of them almost by voluntary principles, many of them in a central city of a region, lead part of the organization, and then realize horizontal joint of each part.

Since the reform and opening up, economic layout and structure adjustment, although there has been some progress, the situation has not changed fundamentally irrational and deep-seated contradictions and more prominent, resulting in economic growth rate was significantly lower than the domestic advanced regions. This not only seriously affected the improvement of economic efficiency, is not conducive to the healthy development of the economy overall. Currently, the regional economic development following problems: economy backward, irrational industrial structure. Due to the long-term impact of the planned economy, the regional economy has lagged far behind the conversion, companies still do not have to adapt to market selection, survival of the fittest micro-economic operation mechanism, resulting in inefficiency, economic growth and technological progress are very slow ${ }^{[1]}$.

As the country has been relatively little investment in certain areas, investments have a serious shortage of corporate profits remain low level for a long time, almost no self-transformation, self-development capabilities. County economy is the cornerstone of the regional economy, there is no strong overall county economy that would not have a strong regional economy. The county has long been plagued by economic backwardness of the region's economic development. In short, the system is not new, resulting in lack of economic vitality. Financial difficulties, resulting in less total economy, people's living standards are not high. If these conflicts are not resolved, the gap with the developed provinces backward areas will continue to widen. 


\section{Significance of Highly Skilled Personnel Training Based on the Regional Economiy}

Due to the highly skilled personnel talent requires a relatively complete developed chain, which involves training of highly skilled personnel, configuration, evaluation, incentives and other various aspects of security. These links if fragmented, highly skilled personnel training will result in blindness and mobility disorder, seriously affecting effective regional development of highly skilled personnel, can't meet the needs of regional economic development. Therefore, for the regional economic development of highly skilled personnel development problems in integrating all aspects of the development of highly skilled personnel, the formation of an effective system of interaction, is of great significance and necessity ${ }^{[2]}$.

It is conducive to the formation and development of industrial clusters in the region. Regional economic and industrial clusters, the mutual promotion and common development, and sustainable development of industrial clusters, is inseparable from the pre-training highly skilled personnel. Zhejiang create regional characteristic economy, nurture and develop a large number of industrial clusters, the secret lies in front of the train to master a large number of modern manufacturing technologies, processes and skills of highly skilled personnel.

It is conducive to the efficient allocation of regional human resources, and the comprehensive, coordinated development of regional economy and society. Integrated development can meet the needs of regional economic development, high-skilled personnel, can reduce the waste of educational resources, avoid disorderly flow of highly skilled personnel to achieve the optimal allocation of resources; also conducive to regional incremental acceleration highly skilled personnel and stock improvement. This will not only alleviate the current shortage of skilled workers widespread phenomenon. Solve the worries of regional industrial development, but also the regional economy sustainable, stable and healthy development of objective needs, is the call of the times, is to establish a corporate image of the real needs; also integrate education resources, the development of vocational education in an effective way to broaden the space for regional social harmonious relations, scientific development, education strategy and other major ${ }^{[3]}$.

\section{Construction of Highly Skilled Personnel Training System Based on the Regional Economy}

Highly skilled personnel training system based on the regional economy refers to economic development in the region, in order to effectively carry out a system of regional development highly skilled personnel, the government should play the main role in macroeconomic regulation and guidance, building on regional economic development strategy under the guidance of the early warning mechanism of supply and demand highly skilled personnel and diversified training mechanism, mechanisms, evaluation and incentive mechanism unified configuration, retention and attraction mechanisms and effects of feedback mechanism integrated into an interactive one six aspects of highly skilled personnel development system. As shown below ${ }^{[4]}$. Fig.1 shows the construction of highly skilled personnel training system.

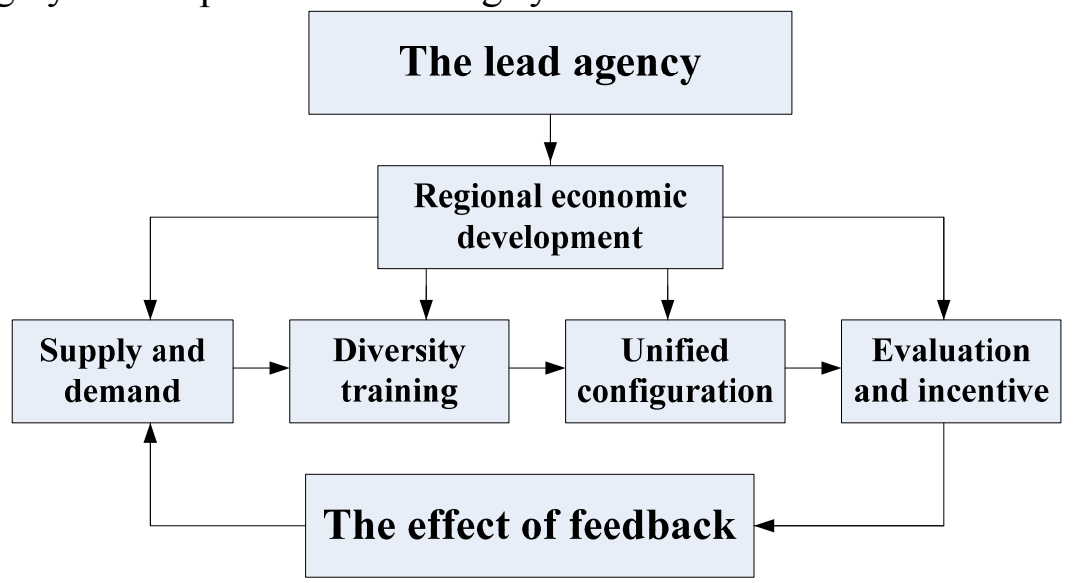

Fig. 1 The construction of highly skilled personnel training system 
Government, business and skills training institutions are as an important body of highly skilled personnel development system and its role in the development of human resources through the various links. In particular, the government should establish a regional coordination mechanism developed by highly skilled personnel, the establishment of a dedicated lead agency, and play its important role in macroeconomic regulation and guidance to integrate the development highly skilled personnel in all links, breaking administrative barriers within the region, according to the regional economic development strategy, plan the development highly skilled personnel various items of work.

Diversity training mechanism requires highly skilled personnel according to the regional economic development strategy, forecasting regional economic development and upgrading of industrial structure of local trends, combined with a warning signal highly skilled personnel to provide early warning mechanism of supply and demand, the development of highly skilled personnel training strategy for industrial restructuring and industrial upgrading and do highly skilled personnel reserve to serve local economic development, which includes training and diversification of cultivation diversification.

Unified configuration mechanism of highly skilled personnel avoid vicious competition among disorderly flow of highly skilled and highly skilled personnel of enterprises, the development highly skilled personnel regional bodies should establish a regional leader in the talent market, which is based on the stock of highly skilled personnel by talent market guide the rational flow of talent, highly skilled personnel allocated to the most reasonable and can create value, the most efficient place. Regional economic cooperation also requires that people must break the original fixed frame of mind, weakening the concept of administrative divisions and strengthen economic development and share ideas and reach consensus on the integration of human resource development

\section{Training Strategy of Highly Skilled Personnel}

Local colleges and universities play its due role in the training highly skilled personnel in the region, strengthening the platform and link local colleges and universities in the area of training highly skilled personnel, but is especially important in local colleges and universities to further rationalize the personnel training in rank, optimize the allocation of resources between the main body of each culture to construct mechanisms involved in regional training highly skilled personnel, the formation of collaborative participation. Resources of regional economic development and highly skilled personnel training can be achieved based on the effective combination of both ${ }^{[5]}$. Fig. 2 shows the Fig. 1 shows the construction of highly skilled personnel training system.

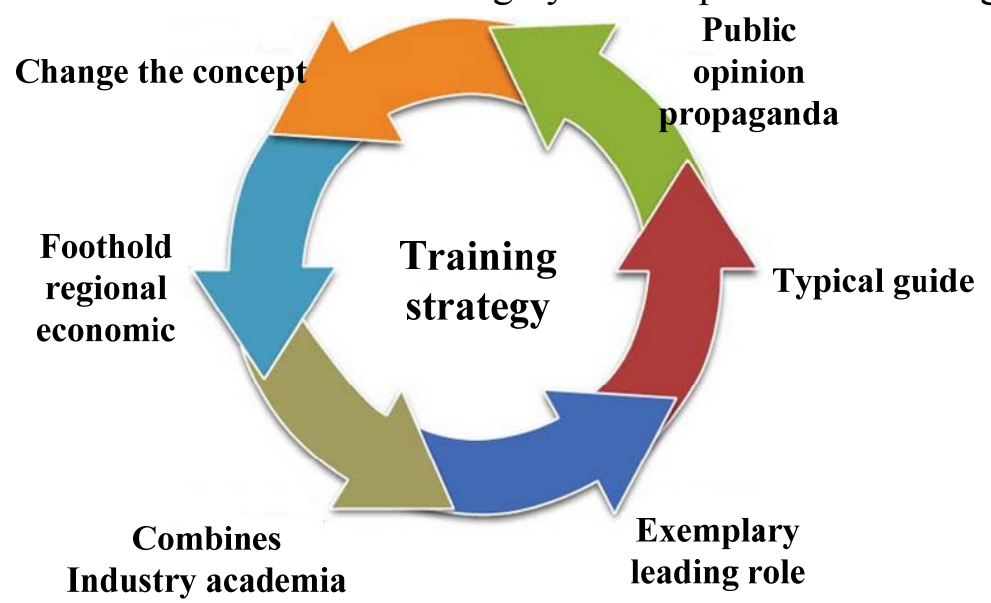

Fig. 2 The training strategy of highly skilled personnel

We must change the concept, establish highly skilled personnel training services for regional development, to adapt the concept of the market economy, and actively serve the regional economic and cultural development. Based on regional economic development status of personnel needs, accurate positioning, Distinctive, personalized path of development, the rational allocation of resources, improve operating efficiency. According to the needs of economic development initiative 
to adjust the professional setting, not only from the current reality, but also a forward-looking, according to the changes of industrial structure and technological structure, adjusting long, short-term professional scale.

Universities should actively exchange and extensive cooperation with local governments, businesses and community to achieve industry-academia combined. Such enterprises by university personnel into their own technological strength, we can also make an inventory, the development of enterprises, and promote regional economic development. On the basis of existing resources, make full use of the university, colleges and universities in developed countries through exchanges and cooperation, and establish a talent pool as soon as possible to accelerate scientific research and knowledge-based enterprises to truly become a power source.

The enterprises train highly skilled personnel work with balanced development, the government should be held regularly corporate training highly skilled personnel, experience and practice evaluation, using the experience exchange, promotion of different industries, different types of business training highly skilled personnel evaluation, on-site observation outstanding achievements corporate training highly skilled personnel work. In short, in order to achieve the rapid development of the regional economy, must be combined with highly skilled personnel training, a positive interaction to build up a diversified investment in personnel training system, and to enable economic development to obtain continuous power

\section{Conclusions}

Nowadays, there still exists a distance between the polytechnic; education and the need of talents demanded by the regional; economic; development. It is necessary for higher vocational education to face the development of regional economy to set and adjust the majors, and take the full advantage of regional resources. The talent people of high technical ability are the most pressing needs. So the development of higher vocational education can improve the pedagogue's labor skills, and achieve maximum its life value. In order to promote the development of regional economy, the times are our great proposition gifts. Therefore, the higher occupation education and region economy is benign and interactive. The higher occupation education must be based on the regional economic development, seeking to rely on the industry: with the advantages of specialty as the core, from the aspects of strengthening own construction.

\section{References}

[1] DAVID C MOWERY, RICHARD R NEISON,BHAVEN N SANPA-Tetal .Ivory Tower and industrial Innovation :University Industry Technology Transfer Before and After the Bayh-Dole Act[M].California: Stanford University Press,2004..

[2] Wei L and Y.H. Tang A Game Analysis on University-Industry Cooperative Innovation [J].Systems Engineering, 2002, 20(1):28-31.

[3] Thammarak Moenja.k, Christopher Worswick. Vocational Education in Thailand: A Study of Choice and Returns. Economics of Education Review,2003, 22(1):99-107.

[4] Jacobs WN, Grubb. The federal role in vocational-technical education[J].Community College Research Center Brie,2003.

[5] Joanna K it-Chun Lam .Shortage of highly skilled workers in Hong Kong and policy responses [J].Journal of international Migration and integration, 2000, 1 (4):405-425. 